\title{
The Empirical Study on the Relationship between Chinese Residents' saving rate and Economic Growth
}

\author{
Zhaoyi Xu ${ }^{1, a}$, Delong $\mathrm{Ma}^{2, \mathrm{~b}}$ \\ ${ }^{1}$ College of Finance and Statistics, Hunan University, Changsha 410082, China \\ ${ }^{2}$ Guanghua School of Management, Peking University, Beijing 100871, China \\ axuzhaoyi@sas.upenn.edu, bmadelong@pku.edu.cn
}

Keywords: Chinese Residents’ saving rate; Economic Growth; Economic Growth;

\begin{abstract}
Chinese economy has grown rapidly with the advancement and implementation of Reform and Opening-up policy. However, compared with the developed countries, The GDP per capita of China is still staying at a poor level. Besides, under the globalized economic development trend, it is inadvisable to maintain the previous extensive development mode and we should pace up in upgrading. After a comprehensive analysis of the economic growth, the resident saving rate, among all factors, shows a significant influence on the economic development, which has been verified by researchers in many empirical studies. The paper collected the statistical data of China from 1998 to 2015 and constructed the regression analysis model based on the neoclassical growth theory and Solow model to analyze the relationship between the Chinese residents' saving rate and economic growth rate. The Granger causality between the two was also studied and analyzed through Granger causality verification.
\end{abstract}

\section{Introduction}

The paper successfully made the following conclusions: there is a long-term balanced relationship between the resident saving rate and economic growth. The resident saving rate doesn't belong to the Granger cause of economic growth while the economic growth turns out to be one of the Granger cause of the resident saving rate. This study provides the theoretical basis for the policy-making of the decision-makers in China. Since the savings in China didn't transform into the investment as expected, the next step of policy-making should focus on the improvement of consumption level, namely, stimulating the resident consumption, to realize the economic growth by expanding the domestic demands.

In recent years, the Chinese economy has grown rapidly and many scholars carried out the studies on the sustainability and internal motives of the economic growth in China. These research outputs have offered the reference for the government's policy-making. Among various influential factors, the consumption level would leave a noticeably influence on the economic growth. Considering the competing relation between consumption and saving, the resident saving rate undoubtedly remains as a significant influential factor. The saving rate keeps rising under the background of the rapid economic growth in China and domestic and foreign researchers have dived into the relationship between the two. In 2008, the subprime mortgage crisis in the United States triggered the global financial crisis, which significantly affected the net export scale of China. The enlarged investment from the government realized the effective stimulation for the economy in a short term and maintained the fast economic development. However, many problems have also occurred in such a growth, such as the overburden of government debt and anemic momentum after the fast growth, which all need us to further analyze the economic development.

By now, the economic growth in China is in a reform and transformation period, which is expected to jump out of being driven by investment in the previous stage and put more efforts in realizing the 
endogenously-driven economic growth, which requires the effective expansion of the domestic consumption demands. However, the current consumption demands in China appear to be not very satisfying and the situation of high saving and low consumption hasn't been significantly improved. Therefore, it is necessary to further dive into the relationship between the saving rate and the economic growth, to analyze the economic fluctuation caused by the change in the saving rate and offer the reference for the regulation policy-making in China. This is also the main objective of this study under the current circumstance. On this account, the study carried out the empirical analysis on the relationship between the resident saving rate and the economic growth, which is of great theoretical and practical significance.

\section{Literature review}

The academia is long concerned with the relationship between the resident saving and economic growth. Keynes studied the relationship as early as in 1936. His analysis was mainly based on the multiplier theory, with the proposition that the increase in the investment scale could effective drive the economic growth and the fast economic development would bring in more investment activities, indicating a positive correlation between the economic growth and the investment multiplier. The investment multiplier is exactly the reciprocal of the saving rate. Therefore, from this perspective, the increase in the saving rate would be associated the decline in the speed of the economic growth, indicating a negative correlation between them. After a variety of studies, the influence left by the saving rate appears to be uncertain in different periods. Gazi A (2009) identified the positive correlation between the saving rate and the economic growth, inferring the imbalance of social wealth distribution as the poor's wealth constantly flowing to the rich. That's the reason why the rich have higher marginal saving rate, which could motivate the economic growth. R. T. Dalimoy (2012) studied the actual data of 21 countries and analyzed the internal relation between the investment and the saving rate. It was found that there was a significantly positive correlation between the two, thus affirming that the high saving rate wasn't noticeably obstructing the economic growth. Nurudeen Abu (2014) applied the data of 32 countries in his study whose results showed that the increase in the resident saving rate led the growth in the investment and thus promoted the fast development of economy.

\section{Empirical analysis of the relationship between Chinese residents' saving rate and economic growth}

By now, many scholars have studied the the relationship between saving rate, investment rate and economic growth rate and the correlation between the saving rate and the economic growth rate has always been a key focus of these studies. The economic growth momentum of China has somehow slowed down. After the high speed period, the Chinese residents' saving rate has also stayed at a high level. The saving rate is bound to be affected as the economic growth slows down. In the new economic trend, it is hard to effective drive the Chinese economy simply relying on the investment. Therefore, the expansion of domestic demands should be taken as the major approach to drive the economic growth. In such a case, the paper used the statistical data from 1995 to 2015 in China to analyze the long-term balanced relationship between the saving rate and the economic growth, followed the elaboration on the Granger causality relationship between the two through the Granger causality verification

\subsection{Related theories}

Neoclassical growth theory puts forward that it is possible for underdeveloped countries with low capital stock per capita to realize the economic growth and the development speed is faster than that of the developed countries with high capital stock per capita. In this way, the economic gap between the countries will be gradually narrowed.

According to the Solow growth model, in a short term, high saving rate could motivate the fast growth of the output, while the endogenous growth theory believes that the marginal revenue of the 
capital will not decrease progressively, so the fast-pacing economic growth caused by the high saving rate also remains long-lasting.

The theories above all consider that the high saving rate would drive the rapid economic growth and many underdeveloped countries also followed this path to raise the economic growth rate, increasing the credit loan scale through high saving rate and further expanding the investment scale to realize the economic growth under the effect of investment multiplier. Meanwhile, the rapidly growing economy would elevate the saving capability of individuals and further push up the saving rate. Based on the analysis, the paper proposed the following hypothesis: the elevation of saving rate would positively influence the economic growth rate which would in return bring up the saving rate.

3.2 Modelling

The empirical analysis in this paper was based on the Cobb-Douglas production function.

$\mathrm{Y}=\mathrm{AK} \alpha \mathrm{L} \beta$

In the equation above, $\mathrm{Y}$ represents the actual gross output, $\mathrm{A}$ is the total factor productivity, $\mathrm{K}$ is the capital investment scale, $\mathrm{L}$ is the labor investment amount and $\alpha$ and $\beta$ represents the share of capital and labor in the gross output.

The increasing GDP per capita also indicates the growing income level per capita. However, the GDP of China is rising up quickly while the GDP per capita remains low. The main explanation is that the population is also noticeably expanding at the meantime of rapid economic growth and the two growth rates are not inconsistent. Since China has the largest the population in the world, it would be more reasonable to analyze the economic growth level by using the standard of per capita. Therefore, this study also used the growth rate y of GDP per capita to measure the economic development.

The saving rate reflects the proportion of the income that residents transfer to the saving. In this study, the saving rate is presented by a ratio of saving increment to the nominal GDP. In the economic development, the saving remains as the major source of the capital investment, so it will directly influence the scale of capital stock. In other words, the high saving rate could help to realize the fast expansion of capital stock. On this basis, the paper measure the capital with the indicator s of the saving rate and one of the assumptions in this study is that all savings could be effectively transferred into capital.

Considering that the data of labor investment is hard to be exactly obtained, the labor growth rate in this paper is counted as the natural growth rate of population with the assumption for A remaining unchanged.

After taking the logarithm of the equation, the basic model used in this paper could be obtained. $\mathrm{yt}=\mathrm{c}+\alpha \mathrm{st}+\beta \mathrm{pt}$

In the equation above, $\mathrm{c}$ is a constant term. The primary data used in this paper is all obtained from the official website of National Statistics Bureau.

3.3 Empirical test

3.3.1 Descriptive analysis

Figure 4-1 shows the fluctuation of resident saving rate during 1998 and 2015 in China 


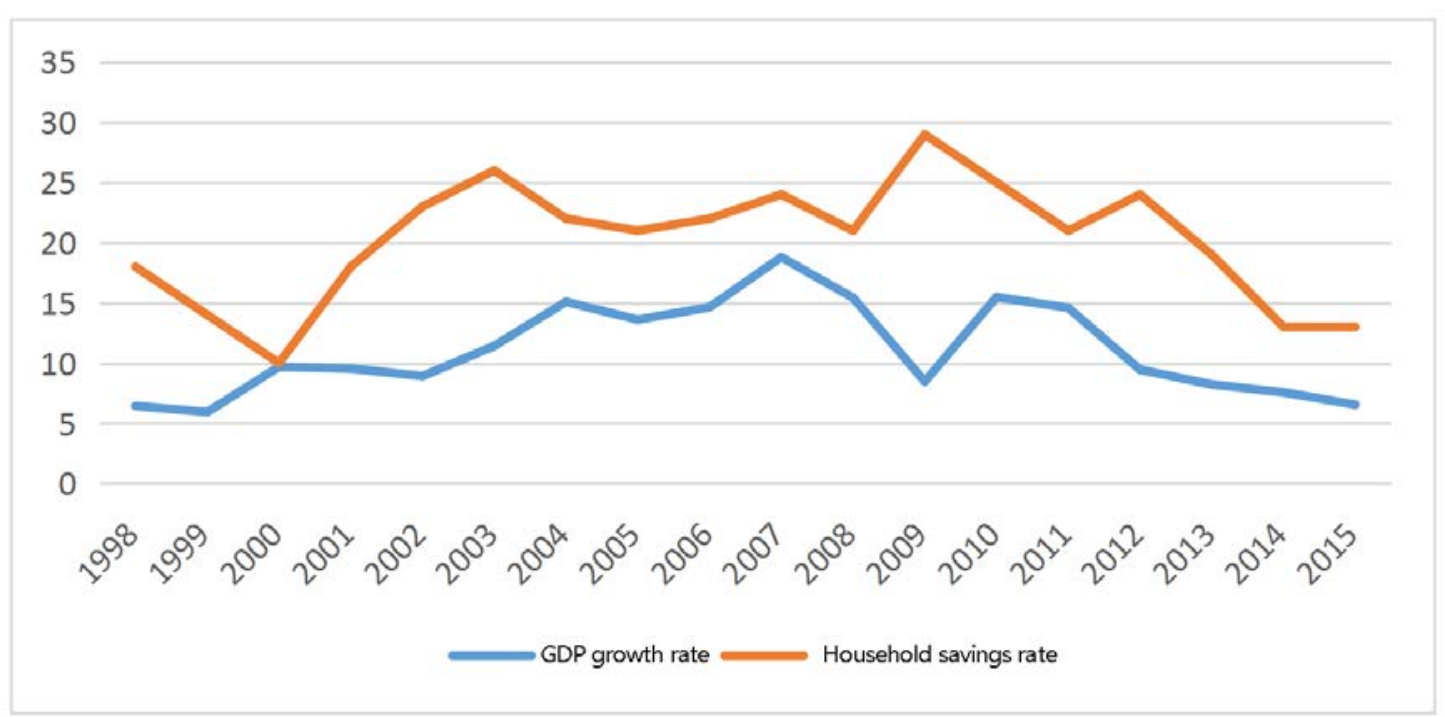

Figure 1 Fluctuations of resident saving rate and GDP growth rate

It could be inferred from the figure that generally speaking, except for particular years, the fluctuation of the resident saving rate is very similar to the fluctuation of the economic growth rate as they almost remain consistent in the fluctuation direction. Therefore, certain causality relation could be assumed between the high saving rate and the fast growing economy.

\subsubsection{Co-integration test}

Before running the Granger causality test for the resident saving rate and the economic growth rate, the time variable sequence needs to go through the co-integration test first, which could avoid the issue the spurious regression. The paper adopted EVIEWS6.1 to run the unit root test, realizing the analysis of the sequence stability. The research result shows that the sequences in this paper are all integrated process, which means they all pass the unit root test, effectively avoiding the occurrence of spurious regression.

Besides, since all sequence are integrated process, they could be proceeded to the co-integration test to demonstrate the long-term equilibrium relationship between the variables and construct the regression analysis equation based on the least squares. The regression coefficients of all variables are obtained to further yield the co-integration formula and the major equation variables, as shown below:

$$
\mathrm{yt}=0.761+0.223 \mathrm{st}+0.122 \mathrm{pt}
$$

The goodness of fit function of the equation is R2=0.342 and the DW test value is 1.972 .

First, the model is tested. The coefficient of goodness of the model is low, remaining only 0.342 , because there are many factors affecting the economic growth. The model constructed in this paper does not include all the factors, but only for analyzing the relationship between the saving rate and the per capita GDP. Therefore, the low goodness of fit is acceptable, considering that this paper is not intended to analyze all the elements of economic growth, but only focus on the impact of the resident savings rate. The DW value of this model is close to 2 , which proves that there is no autoregressive issue in the variables.

Secondly, the regression analysis model is applied to analyze the equilibrium relationship between the two variable. The resident saving rate has a positive regression coefficient of 0.233 , indicating a positive correlation between the resident saving rate and the per capita GDP growth rate. To put it in another way, the improvement of the resident saving rate can lead to the increase in the per capita GDP growth rate, suggesting the inner relationship between the two.

Finally, the co-integration relationship between the two is analyzed. The stability of the residual sequence is also analyzed. The $\mathrm{T}$ statistic corresponding to the residual sequence is -0.52 , which is less than the critical value at the significant level of $1 \%$. Therefore, it can be concluded that there is a co-integration relationship between the two variables, which confirms that a long-term equilibrium relationship exists between the resident saving rate and the per capita GDP growth rate. Therefore, it is possible to further examine the Granger causality. 


\subsubsection{Granger causality test}

To analyze the relationship between the Chinese resident saving rate and economic growth more accurately, this paper analyzes the causal relationship between the two and uses the Granger causality test to make further analysis based on the results of the co-integration test. Table 4-1 shows the result of the Granger causality test.

Table 4 Granger causality test result

\begin{tabular}{|l|l|l|l|}
\hline Lag length & Causality relation & F value & P value \\
\hline \multirow{2}{*}{2} & Granger cause of y being not s & 0.098733 & 0.89632 \\
\cline { 2 - 4 } & Granger cause of s being not y & 1.987234 & 0.18803 \\
\hline \multirow{2}{*}{3} & Granger cause of y being s & 4.235094 & 0.01823 \\
\cline { 2 - 4 } & Granger cause of s being y & 1.802334 & 0.18343 \\
\hline
\end{tabular}

It could be inferred from the table that when the lag length is 2, the saving rate and the economic growth rate have no Granger causal relationship; when the lag order is 3, the economic growth rate is the Granger cause for the saving rate while the saving rate is not the Granger cause for the economic growth. It shows that the actual level of GDP in the previous period will explain and predict the level of the subsequent saving rate, that is, part of the actual income obtained can be transferred into to the savings, which can explain the significantly positive correlation between the actual GDP and savings increment. Based on the neoclassical economic growth theory, the high saving rate will drive the expansion of the investment scale, and then realize the rapid growth of the economy under the multiplier effect. Therefore, the high saving rate will lead to the rapid growth of GDP. In this paper, the empirical results did not draw such a conclusion, but demonstrated that the economic growth is the Granger cause for the resident saving rate. The results obtained in this paper are consistent with those obtained by Hu Yaqin (2009) and Wang Wei (2013).

\section{Conclusion}

The major conclusions of this study are drawn below:

There is no obvious Granger impact of the current Chinese resident saving stock on the actual GDP level and its growth rate. Secondly, China's actual GDP has a Granger influence on the resident saving rate, which means, the saving rate does not have a significantly positive impact on economic growth, while China 's actual GDP has a significant impact on the saving rate. As a result, higher income growth has driven the increase in saving rates. However, the contribution of the saving rate to the economic growth is weakened due to the stable investment demand and low consumption demands of Chinese residents.

\section{References}

[1]Gazi A. Uddin,Khorshed Alam,Jeff Gow. Population age structure and savings rate impacts on economic growth: Evidence from Australia[J]. Economic Analysis and Policy,2009.

[2]Anya Khanthavit. Setting self-discipline saving rates for Thai income earners in a risk-management framework[J]. Kasetsart Journal of Social Sciences,2011,:.

[3]R.T. Dalimov. On Methodology of Computing the Union's Domestic Savings Rate Prior to Creation of Economic Union[J]. Current Research Journal of Economic Theory,2012,1(1).

[4]Tapen,John Whalley,Xiliang Zhao. Housing price and household savings rates: evidence from China[J]. Journal of Chinese Economic and Business Studies,2013,11(3).

[5]Nurudeen Abu,Mohd Zaini Abd Karim,Mukhriz Izraf Azman Aziz. Low Savings Rates in the Economic Community of West African States (Ecowas): The Role of the Political Instability-Income Interaction[J]. South East European Journal of Economics and Business,2014,8(2). 